\title{
Actualization and ways of system approach to risk management in occupational health and safety
}

\section{Andrii Bochkovskyi ${ }^{A}$}

Received: June 20, 2020 | Revised: June 22, 2020 | Accepted: June 30, 2020

DOI: $10.33445 /$ sds.2020.10.3.8

\begin{abstract}
Substantiation of the need to introduce a system approach to risk management in occupational health and safety management systems and identification ways to implement it. 1 . To identify the existing disadvantages of the practical implementation of the stages of the risk management process in occupational health and safety. 2 . To substantiate and propose mathematical models for the objective implementation of the Plan procedure of the risk management process in occupational health and safety. 3 . To analyze the functionality of existing automated systems of the dangers minimization to ensure the effective functioning of Do - Chek - Act procedures in occupational health and safety. 4. To propose the automated management system of occupational health and safety at the enterprises for objective implementation of Do - Check Act procedures within the OHS management systems of the enterprises. Analysis of scientific and technical literature and regulations in occupational health and safety, probabilistic and statistical methods, Markov analysis. It is established that the existing methodological approaches to risk management in occupational health and safety ensure for the implementation of only four of the eight necessary stages (stages of risk evaluation) of the relevant process provided by the PDCA methodology. Mathematical models, which allow to set the relationship between occupational health and safety costs and the risk level, as well as to set the probability of not exceeding the accumulation in the employee of the consequence of certain harmful factors impact and occupational injuries at random during the workshift are substantiated and proposed for use. The main disadvantages of the existing automated systems of risk minimization in occupational health and safety, which are the impossibility of minimizing the negative "human factor" signs and the impossibility of prompt normalization of the parameters of harmful production factors on the employee over time are identified. The automated management system of occupational health and safety, which allows to conduct constant monitoring and prompt correction of parameters of impact on the employee of negative factors within the values set by results of risk evaluation is substantiated and offered for application.
\end{abstract}

Key words: occupational health and safety, risk evaluation, risk minimization, occupational danger, automated system.

\section{Introduction}

The problem of reducing their own labor resources, especially the economically active, highly qualified population, has always been one of the most pressing in our country. It is especially acute against constant dynamics of demographic aging. Thus, according to UN criteria, a population is demographically old if the number of people aged 60 and over is $12 \%$ of the total population. In Ukraine, this number is averages $21 \%$ (Bochkovskyi A. P., 2019). Given this, the issue of preserving the life and health of the economically active population of Ukraine in

\footnotetext{
A Odessa National Polytechnic University, Odessa, Ukraine, Dr. Sc. (Tech.), Assoc. Prof., e-mail: andrew.bochkovsky@gmail.com, ORCID: 0000-0002-4166-3148
} 
the production conditions is urgent. The most effective, world-renowned strategy for ensuring and maintaining the highest possible level of occupational safety and health is a workplace danger prevention strategy. It provides for the development of preventive safety activities based on the procedure of evaluation the relevant risks and the development of organizational, technical, legal, treatment and prevention and other activities and means to minimize them. Ukraine, as a state, has undertaken to gradually, over the coming years, reform its own legal framework, through the implementation and harmonization of relevant EU regulations. Thus, during this period, all economic entities, without exception, should automatically transition to a fundamentally new, for many, risk-based strategy to ensure comfortable, safe and healthy working conditions.

One of the first steps to such a transition was the adoption of the Concept of reforming the system of occupational health and safety management system in Ukraine (here in after the Concept) and the drafting of a new Law of Ukraine "On occupation health and safety of employee" which is submitted for public review and discussion and which should replace the Law of Ukraine "On occupation health and

\section{Material and methods}

Problems of reforming OHS management systems at enterprises through the introduction of proactive principles of minimizing occupational dangers, in particular the use of new methods for evaluation the probability of dangers origin was considered in following scientific studies. However, the analysis of these studies determined a number of unresolved issues and shortcomings.

Thus, in the work of Lesenko G. G. (2011), a method, which is based on a mechanism for evaluation the existing functions of $\mathrm{OSH}$ management system and qualitative solution of its main tasks, but without reference to the real causes of occupational injuries and occupational diseases is proposed. Also, the proposed safety". The Concept provisions and new law requirements include the creation the fundamentally new systems of occupational health and safety management (OHS management system), whose the functioning is based on the principles of risk management the of occupational dangers origin at enterprises (Concept of reforming the labor protection management system in Ukraine). For this purpose, economic entities should conduct the risk evaluation at each workplace and to develop and implement the appropriate safety activities and means based on results of this evaluation. This step is definitely necessary in terms of improving the efficiency of modern OHS management systems, but in this context two questions arose, however: whether such an implementation is possible in practice and whether it is possible at a given time. In order to do this, the existing principles and methodological tools of risk management in occupation health and safety should be analyzed and the specific ways and activities to restructure existing OHS management systems at enterprises into modern risk management systems and to increase their efficiency in full compliance with international regulations in occupational health and safety should be developed.

methodology does not allow the implementing a forecast for the operation of OHS management system for future periods, which is necessary to evaluate the efficiency of the applied safety activities and means.

The study (Kruzhilko O.E., Watchman Ya.B., Lutak Z.I. and Prachnikov N.A., 2017) is devoted to the improvement of methodological approaches to risk evaluation in occupation health and safety. The existing evaluation methods were analyzed by the authors and it is noted that their large number, as well as the lack of unified terminology and structure of the tools can lead to erroneous results. It is also underlined that the practical implementation of risk-based approach in OHS management 
systems is complicated due to the lack of a universal approach to risk evaluation and relevant automated systems that could greatly simplify the implementation of risk management and improve the quality of preventive safety activities.

In the article (Bochkovskyi A. P., 2016), a mathematical model to evaluate the risks, which should be based on the theory of Markov processes, within the OHSmanagement system was proposed to use. However, the lack of information concerning its construction and capabilities does not allow for the objective conclusions about its efficiency. In addition, the proposed model is based on expert assessments, which significantly reduces the accuracy of the result.

In (Tretyakov O. V., Nestereko S. V., Doronin E. V., Golovenko M. M., 2018) the possibility of implemetion risk theory to determine the level of impact of harmful and dangerous production factors on the employee was analyzed. A method of evaluation the integrated risk in the work area, taking into account the residence time in the area of dangerous factors by employees, based on the probabilistic model of the impact of harmful factors on the health of employees was proposed by the authors. The obtained dependencies are recommended to be used for attestation of workplaces and determination of priority of OHS activities taking into account the level of industrial and occupational risks. However, the developed evaluation method does not take into account the stochastic and dynamic nature of the hybrid impact on the employee of dangerous and harmful production factors, which is in real "man - machine - environment" systems.

In the article (Zdanovskiy V. G., Gogitashvill G. G., Stepanishin V. M., 2016), the experience of modern enterprises that have already revised their policy in the occupational health and safety in accordance with international standards was reviewed. The urgency of the transition to a new risk-oriented model of OHS management system was underlined by the authors. However, in the study, along with a detailed description of the positive changes that are expected as a result of the transformation of the
OHS management system into a risk management system, no directions, in which this transformation should take place were proposed.

In the study (Ismael S. Sánchez - Herrera, Mario J. Donate, 2019), based on changes in occupational injuries, the results of the implementation of a certain positive changes in the OHS management system of various industries in Spain over the past five years were analyzed. These changes are based on the analysis of the identified problems that inhibit the process of effective integration of this system. The main problem, according to researchers, is the insufficient qualification level of OHS specialists and managers of enterprises that are directly involved in the implementation of OHS management system at the enterprise and in the organization of the work process within it. The disadvantage of the study is purely analytical, so its results can be used only as an appropriate basis for developing further directions of implementation of risk-based approach OHS management system.

In the article (Halil V. V., 2018) to improve the OHS management system, a system of indicators based on the ranking of events and noncompliance of production processes at the enterprise with the requirements of occupational health and safety was proposed to use. The disadvantages of this study are the lack of mathematical substantiation for the use of these indicators, specific models based on them, as well as the lack of bind of indicators to specific causes of accidents at workplace.

The purpose of this study is substantiation the need for a system approach to risk management in occupational health and safety management systems and identification ways to implement it.

Achieving this goal include solving the following tasks:

to identify the existing disadvantages of the practical implementation of the stages of the risk management in occupational health and safety;

substantiate and propose mathematical models for the objective implementation of the 
Plan procedure of the risk management process in the field of labor protection;

to analyze the functionality of existing automated systems of the dangers minimization to ensure the effective functioning of Do - Chek - Act procedures in occupational health and safety;

\section{Results and discussion}

"Concept of reforming the management system of occupational health and safety in Ukraine" approved by the Order of the Cabinet of Ministers of Ukraine is based on the provisions of the EU Framework Directive, which is the basis for a some other directives, laws and regulations in occupational health and safety (Concept of reforming the labor protection management system in Ukraine, Framework Directive No. 89/391/EEC). Relevant documents specify the responsibilities of each employer regarding the need for risks management of danger origin within the health and safety management system by the procedure of their evaluation (Concept of reforming the labor protection management system in Ukraine, Framework Directive No. 89/391/EEC). Based on the results of such evaluation, the employer should develop and implement the necessary organizational, technical and other safety means (Framework Directive No. 89/391/EEC). The Directive states that the employer should have procedures for evaluation and managing risks and involve employees in the implementation of these procedures. In addition, the employer should appoint one or more employees for the risk management procedure (Framework Directive No. 89/391/EEC). Moreover, the appointed employees should have the necessary capabilities for this, namely knowledge, tools and means (Framework Directive No. $89 / 391 / E E C)$. That is, the risk management process should be conducted by the company, although third-party professionals can be involved, as appropriate (Bochkovskyi A. P., 2019). Based on the requirements of the Directive, the question arose, whether what methodological possibilities exist for the practical implementation of the principles of risk prevention for employers and employees. After to propose the automated management system of occupational health and safety at the enterprises for objective implementation of Do - Check - Act procedures within the OHS management systems of the enterprises.

all, the risk management process is quite complex and responsible. General requirements, methodology, methods, recommendations for risk management in occupational health and safety management systems, as well as the principles of construction of OHS management system and relevant terminology are in the following current international regulations: IEC/ISO 45001:2018; OHSAS 18001:2007; OHSAS 18002:2008; IEC/ISO 31000:2018; IEC/ISO 31010:2019, as well as other, including current Recommendations on the construction, implementation and improvement of OHS management system and those referenced in the above standards. A thorough analysis of these standards was conducted in a previous study (Bochkovskyi A. P., 2018; Bochkovskyi A. P., Sapozhnikova N. Yu., Gogunskii V. D., 2017). According to the results of the analysis, it is set that the basic principles of construction and operation of $\mathrm{OHS}$ management systems in terms of risk-based approach are the consistent implementation of a number of procedures known as the PDCA methodology.

This process can be represented as the implementation of the following eight stages Fig.1 (Bochkovskyi A. P., 2018).

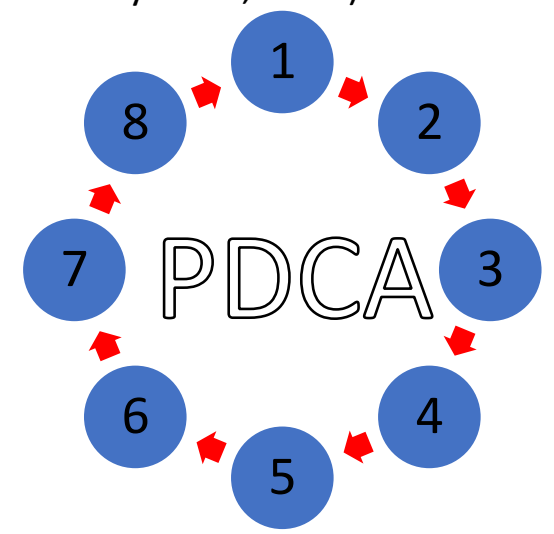

Fig. 1 - Extended cycle 
occupational health risk management, where 1 formulation of purposes and tasks of risk management and identification of available resources to achieve them; 2 -identification of all potential dangers; 3 - determining the probability of a certain danger origin and the severity of its manifestation; 4 - evaluation of the risk level of dangers origin (quantitative risk evaluation); 5 criteria risk evaluation (by the criterion of acceptability); 6 - ranking of risks by priority; 7 development and implementation of safety activities and means; 8 monitoring and correction (according to the PDCA methodology)

If these stages group according to the principles of implementation of certain procedures of the risk management process, PDCA methodology can be finally presented as a consistent and cyclical implementation of three main stages, namely management planning, risk evaluation and risk minimization. (Bochkovskyi A. P., 2019). In this case, the management planning procedure, in accordance with the requirements of the above normative legal documents, aims to determine the amount of resources necessary to achieve and maintain an acceptable risk level of occupational dangers origin throughout the range of identified dangerous and harmful production factors (DHPF) for each workplace. Accordingly, the evaluation procedure is to quantify the probability of occupational dangers origin for each identified factor and for each workplace, and the minimization procedure is constant control and prompt correction of the parameters of the impact of dangerous and harmful production factors on the employee within the set (normalized) values.

However, to implement these procedures in reality is almost impossible due to the following actual problems. The first one is that both the management planning procedure and the danger minimization procedure are methodologically unsecured. That is, to date, there are no methods in which these procedures can be implemented to achieve objective results, in accordance with the purposes of risk management and the requirements of normative legal documents. The second problem is the perfunctory of available methodological support for the most complex and responsible procedure of the management process - the risk evaluation procedure. The perfunctory of methodological support is explained by many factors, the main of which is the bias of known evaluation methods (due to the impossibility to take into account the objective characteristics of random dynamic impacts of dangerous, harmful production and other negative factors on the employee within the real "man - machine - environment" systems), as well as the impossibility of using them by the economic entity (Bochkovskyi A. P., 2019).

Therefore, given the identified problems, it can be concluded that within the normative legal documents to introduce a risk-based approach to modern OHS systems is objectively impossible, not just because the lack of methodological tools for the implementation of basic procedures and relevant competencies of their implementor, but also due to the inability to ensure the principles of cyclicality and consistency of their implementation, as provided for by the PDCA methodology. The latter implies a clear relationship between all procedures of the management process, which in turn can be ensured only by a system approach. Thus, the transition to a new riskoriented concept of OHS management in enterprises requires the introduction of the principles of a system approach to the risk management process, which can ensure cyclical, consistent and objective implementation of these three necessary procedures.

The problems of the lack of a system approach to risk management are very similar to the problem of standardization of $\mathrm{OHS}$ management systems offered by the end of the last century. At that time, the lack of a unified standard was creating problems for the development of international cooperation within improving occupational safety and economic relations. The coordination procedures between national, international and independent certification organizations, in particular, hampered the adoption of the unified document. Misunderstandings were because the lack necessary international legal framework that would be the groundwork for creating the standard. Such the groundwork became the OHSAS 18001 series standard, which allowed 
enterprises from around the world to certify their own management systems, taking into account the specificity of their activities.

The historical experience of adopting the OHSAS 18001 series standard obviously should be taken into account also in developing directions for implementing a risk-oriented approach in OHS management systems. Because such research can be the basis for the development of a promising international standard that would resolve the methodology of risk management in OHS systems.

Therefore, in developing such directions, it is advisable to rely on the following basic principles:

mathematical and other tools that will be used in the development of methodological support for risk management procedures in occupational health and safety should be known, as objective as possible and generally accepted;

the results of the research should be in the form of a ready-to-use product (mathematical models, software product);

the final product should be clear, accessible for use by economic entities (compatible with standard software for personal computers), regardless of the industry, forms of ownership and management (large, medium, small enterprises, etc.).

In accordance with the set principles and purposes of risk management, to implement the procedure of risk management planning in $\mathrm{OHS}$ systems in enterprises, a mathematical model that allows to determine the minimum amount of financial resources needed to achieve and maintain the highest possible level of employee safety was offered (Bochkovskii A.P., Gogunskii V.D., 2018). In this case, the level of occupational safety of the employee can be characterized as the probability that no risk event throughout the range of identified dangerous and harmful production factors (DHPF) will be realized in the relevant occupational danger (Bochkovskii A.P., Gogunskii, V.D., 2018). Accordingly, the risk management planning procedure can be represented as follows (Bochkovskii A.P., Gogunskii V.D., 2018):

$$
\sum_{i=1}^{n}\left[P_{i}+k_{i} a_{i}\left(r_{i}+P_{i}\right)^{-b_{i}}\right] \leq \Phi,
$$

where $P_{i}(i=1, \ldots, \mathrm{n})$ - resources for the implementation and operation of organizational and technical preventive safety activities and means aimed at minimizing the negative impact of $n$ types of DHPF; $\Phi$ - the amount of financial resources of the economic entity for occupational health and safety of the employee during the time when $i$-th DHPF with random intensity $\alpha_{i}$ impacts negatively on the employee; $k_{i}$ - the cost of eliminating the unit of the consequences of the negative impact on the employee of the $i$-th DHPF, $a_{i}, b_{i}$ - the actual excess of the negative impact of DHPF of normalized values at the corresponding costs allocated to protective activities, determined by processing statistical data, $\left(a_{i}, b_{i}>0,\right), r_{i}$ - costs of additional leave, medical and preventive nutrition and other benefits and compensations.

The implementation, within OHS system, the following procedure management process - risk evaluation - primarily requires the setting of opportunities of objective taking into account of specificities of the DHPF impact on employee that occurs within real "man - machine environment" systems. Given the fundamentally different nature of such impact, a prerequisite is a separate evaluation of the consequences of the impact of dangerous production factors (DPF) and evaluation of the consequences of the impact of harmful factors (HPF) on employee. Therefore, if the DPF impact on the employee occurs at a random period during the work shift and generally leads to immediate damage with a certain consequences as injuries of varying severity, the HPF impact on the employee occurs during a certain random periods of the working shift and with random intensity. And the negative consequences of such impact appear over time and have the cumulative character. In this case, to objectify the risk evaluation, it is necessary to take into account not only the process of accumulation of negative HPF impact in the employee during the workshift, but also the process of addressing the consequences of such impact during non-working hours, during regulated workshift breaks and in other cases. 
For an objective mathematical description of the dynamics of these stochastic hybrid processes, which include discrete and continuous components, it is advisable to use a special subclass of Markov processes - Markov processes with drift (Bochkovskyi A.P., 2019). Thus, to objectively evaluate the risk of occupational dangers origin due to the negative impact on the employee of a certain range of HPF, the following expression, which describes the probability of exceeding the accumulation level of negative HPF impact of set hygienic standards was proposed (Bochkovskyi A.P., 2019):

$$
\int_{\sigma}^{\infty} \int_{0}^{\infty}\left[\left(q_{00}(x, \tau)+q_{i k}(x, \tau)\right)\left(1-A_{0}(\tau)\right)+\left(q_{i k}(x, \tau)+q_{i k}(x, \tau)\left(1-A_{1}(\tau)\right)\right] d \tau d x\right.
$$

where $\sigma$ - set hygienic standard (maximum permissible level or concentration of harmful production factor); $\tau$ - time elapsed from the beginning of the workshift (from the beginning of the non-working period) to the moment $t ; x-$ the amount of harmful substances in the employee at time $t ; A_{0}$ та $A_{1}$ - alternating process of changing the working and nonworking periods; $q$-density of the probability of joint distribution of the amount of harmful substances and the time remaining before the change of the alternating process; $i-$ a discrete variable describing the periods of working and non-working change, at time $t ; k$ - a discrete variable describing the state of efficiency of production equipment that produces the harmful production factors, at time $t$.

Accordingly, to evaluate the risk of occupational dangers origin associated with the negative DPF impact on the employee, an expression, which describes the probability of occupational injury by an employee in a random period was proposed (Bochkovskyi A.P., 2019):

$$
\left.\left.\int_{0}^{\infty} q_{k j}^{-}(\tau)\right)\left(1-A_{1}(\tau)\right) d \tau+\int_{0}^{\infty} \int_{0}^{\infty}\left[q_{i j}(x, \tau)\left(1-A_{0}(\tau)\right)+q_{k j}(x, \tau)\right)\left(1-A_{1}(\tau)\right)\right] d x d \tau,
$$

where $j-$ a variable that describes the state of the employee's working capacity, at the time $t$.

The solution of task (1) belongs to the field of convex programming, so it can be solved both by numerical methods and using standard software (Bochkovskyi A.P., 2019). The solution of expressions (2) and (3) is although a complex mathematical problem, but can also be found both by the analytical approach (using the method of fictitious phases of Erlang) and by special packages of computer applications (Bochkovskyi A.P., 2019). Thus, the expressions, proposed for the implementation of management planning and risk evaluation procedures, fully comply with the above three basic principles of developing appropriate methodological support, which is necessary to introduce a risk-based approach to existing OHS management systems of enterprises, institutions and organizations.

The last, third, procedure of risk management process in OHS system - minimization of occupational dangers involves the implementation of constant monitoring and prompt correction of parameters of impact of dangerous, harmful production and other factors in case of deviation from the set values obtained within the first and second procedures.

The implementation of constant monitoring and prompt correction is due not only to the requirements of the guidelines for risk management and construction of $\mathrm{OHS}$ management system, it is necessary given the stochastic and dynamic nature of changes of the parameters of DHPF impact on the employee over time, within the real "man - machine environment" systems. However, unfortunately, the existing principles of modern OHS management system do not provide for such opportunities. Monitoring and correction of parameters either does not occur even, or occurs very inertly within the so-called step control, 
which is conducted by relevant services, heads of departments and others.

Therefore, given the need for continuous monitoring and prompt correction of the parameters identified during the risk evaluation, in order to objectify the minimizing occupational dangers procedure, there is an urgent need to implement certain automated systems that can perform these functions within the OHS system. Such automated systems should solve another very important and complex problem of the risk management process, namely, to effectively minimize the main cause of occupational dangers - possible the "human factor" signs (Bochkovskyi A.P., 2019).

Information and management system of comprehensive control of safety of dangerous production object. The system includes means of obtaining natural data of the technological process and environmental situation from the areas of the dangerous production object at time. This system allows to prevent possible emergencies at chemically dangerous enterprises (objects) by prompt application of preventive activities. The principle of its work is to evaluate the deviations of the actual parameters from the set indicators (patent 2536351 of RF). The main disadvantages of this system are the lack of control over erroneous actions of employees (inefficiency in minimizing the "human factor" impact) and over training level in OHS; limited application, as the system is intended only for implementation in chemically dangerous enterprises; lack of general control over the state of the production environment, which is actually conducted only by two indicators (vapor concentration and the level of losses of harmful and dangerous substances that are stored and used at the enterprise); inability to control over other dangerous production areas, except those where the employee is exposed to DHPF of the chemical group.

The integrated monitoring system of the objects under control allows to significantly increase the safety level of the enterprise by conducting constant chemical and radiation control, as well as ensuring the required level of fire and explosion safety of the enterprise (patent 2417451 of RF). The disadvantages of the system are: the solution of a very narrow range of issues related exclusively to the danger of impact on the employee to chemical and radiation DHPF; insufficient controllability (the system does not provide for the possibility of managing controlled indicators); lack of control over erroneous actions of employees (inefficiency to minimizing the "human factor" impact), especially in dangerous production areas.

The system of early detection of emergencies allows for continuous monitoring of current values of potentially dangerous technological parameters. In the automatic mode provides prompt response of the relevant services of the enterprise, as well as government agencies at different levels of threat (or occurrence) of emergencies. Due to the use of instrumental monitoring methods, the system minimizes the impact of the "human factor" in detecting the threat of emergencies (patent 53753 of Ukraine). The disadvantages of the system are: lack of universality (the system is aimed at addressing a narrow range of issues related only to chemical contamination of the area or objects); impossibility of automatic elimination of the reasons of occurrence or threat of occurrence of an emergencies (within system only data collection, their processing and the alarm system about deviations from the set normalized values is conducted); lack of control over the erroneous activities of employees, which can be a direct or indirect cause of the emergency (insufficient effectiveness in minimizing the "human factor" impact).

The system of automated comprehensive protection against occupational dangers is aimed at the implementation of comprehensive protection of employees from the impact of dangerous, harmful production and other factors within "man - machine - environment" systems. In particular, the system minimizes certain "human factor" signs associated with inadequate knowledge level of occupational health and safety in the workplace. However, its significant disadvantage can be considered the inability to protect the employee within the "man - machine - environment" system from the negative impact of other "human factor" signs, caused, for example, unconscious actions (inaction) of 
employee, due to its appropriate psychophysiological state and reactions (patent 118077 of Ukraine).

It should be noted that the general disadvantage of existing automated systems can be considered ignoring the fact that the process of normalization of parameters of HPF impact always requires a certain period (from the moment when the sensor recorded deviation from the set normative value to moment of normalization) in which the employee accumulates negative consequence from the impact of these factors. This phenomenon is a random process and can be repeated many times during the workshift, significantly increasing the negative impact on the employee of other HPF of the psychophysiological group (static, physical activity, monotony, etc.), which are inherent in the workplace.

Given the wide range of harmful production factors that impact on the employee during the workshift, the process of increasing the negative impact of these psychophysiological factors has a certain cumulative effect, which can trigger negative psychophysiological reactions of the employee (loss of consciousness, reflex errors, etc.), in turn lead to accidents, occupational injuries, occupational poisoning, deaths (including group), industrial accidents and catastrophes. In addition, the existing automated systems do not provide comprehensive achievement of purposes and tasks of occupational health and safety management at the enterprise.

In order to eliminate these disadvantages, the following automated OHS management system was developed, which aims to ensure (Bochkovskyi A. P., Sapozhnikova N.Yu., 2019): the presence of the necessary, coordinated relationships between all its elements, which ensure the implementation of obligatory activities for OHS management at the enterprise in accordance with purposes and requirements of normative legal documents; full and prompt protection of employees from the consequences of negative "human factor" signs, due to the technical impossibility of the performing devices to instantly normalize the parameters of the negative DHPF impact on the employee; a significant increase of the protection level of human-machine systems from the negative impact of dangers caused by unsatisfactory psychophysiological state of the employee, by conducting appropriate testing before the start of the workshift; increasing the safety level of technological processes by constantly monitoring over psychophysiological state of the employee and prompt prevention of the negative consequences of deterioration of such state in the workplace, on which it depends the safety level of technological processes and the enterprise as a whole; minimization of the negative DHPF impact of psychophysiological group, by ensuring the implementation of qualitative and quantitative characteristics of the developed individual rational modes of work and rest for each workplace in the enterprise; activities to reduce the number of cases of occupational injuries and occupational diseases for organizational, psychophysiological and technical reasons, by operational comprehensive control over all sources of danger at the enterprise; reduction of risks of occurrence of individual and group deaths at the enterprise, as a result of negative actions or inaction of the employee caused by sudden psychophysiological reactions of an organism which lead to loss of control over technological process; elimination (minimization) of the majority from the known nomenclature of risks of occupational dangers origin; improving the process of control over the education and training of employees in occupational health and safety and industrial safety, as well as the process of certification of workplaces, which significantly reduces the costs of the enterprise for its implementation; conducting operational video surveillance of workplaces with a high degree of risk of occupational dangers origin; management of rational modes of work and rest set at the enterprise; increasing the social attractiveness of the enterprise, by significantly increasing the safety level of technological processes, reducing the level of occupational injuries and occupational diseases; increasing the economic effect at the enterprise by increasing the productivity level, reducing the number of insurance payments. 


\section{Conclusions}

1. It is established that the existing methodological approaches to risk management in occupational health and safety ensure for the implementation of only four of the eight necessary stages (stages of risk evaluation) of the relevant process provided by the PDCA methodology. Other stages, in particular risk management planning and minimization, within the requirements of existing legal documents on risk management in occupational health and safety, are generally without methodological support. The main disadvantages of the proposed evaluation methods are not taking into account the real characteristics of the random impact of negative factors on the employee over time.

2. Three mathematical models that allow to objectively and comprehensively implementing the Plan procedure within the OHS management system are substantiated and proposed for use. The proposed models allow to set the relationship between occupational health and safety costs and the risk level due to the impact on the employee of each identified negative factor, taking into account the random nature of such impact over time, as well as to set the probability of not exceeding the accumulation in the employee of the consequence of certain harmful factors impact and occupational injuries at random during the workshift.

3. Based on the analysis, the main disadvantages of the existing automated systems of risk minimization in occupational health and safety, which are the impossibility of minimizing the negative "human factor» signs and the impossibility of prompt normalization of the parameters of harmful production factors on the employee over time, as well as the impossibility to ensure the relationship between the controlled parameters of the impact on the employee of these factors and the actuating devices, that does not allow objectively and consistently implement the procedures Do Check - Act of risk management process in occupational health and safety are identified.

4. For the objective implementation of the Do-Check-Act procedures of the PDCA process, an automated OHS management system, which allows constant monitoring and prompt correction of impact parameters of negative factors on employee within the values set by risk evaluation results was substantiated and proposed for use.

\section{References}

Bochkovskyi A. P. (2016). "Theoretical aspects of criteria assess the potential effectiveness of OSH management system". Bulletin of the Lviv State University of Life Safety, Vol. 12, pp. 100-107. DOI: 10.13140/RG.2.1.2413.5444

Bochkovskyi A. P. (2018). Actualization of the scientific principles elaboration on evaluating the risks of occupational danger occurrence. Naukovyi Visnyk Natsionalnoho Hirnychoho Universytetu, Vol. 6, pp. 95-103. DOI: 10.29202/nvngu/2018/14

Bochkovskyi A. P. (2019). "Scientific bases of management of risks of professional dangers". Thesis abstract of Dr.Sc.(Eng.). 05.26.01. Dnipro, Ukraine.

Bochkovskii A.P., Gogunskii V.D. (2018). Development of the method for the optimal management of occupational risks. Eastern-
European Journal of Enterprise Technologies, no. 3/3(93), pp. 6 - 13. DOI: 10.15587/17294061.2018.132596

Bochkovskyi A. P., Sapozhnikova N.Yu. (2019). Minimization of the "human factor" influence in Occupational Health and Safety. Naukovyi Visnyk Natsionalnoho Hirnychoho Universytetu, no. 6. pp. 95-106. DOI: https://doi.org/10.29202/nvngu/2019-6/14

Bochkovskyi A. P., Sapozhnikova N. Yu., Gogunskii V. D. (2017). Legal and organizational issues of improving the labor protection and industrial safety level at Ukrainian enterprises. Naukovyi Visnyk Natsionalnoho Hirnychoho Universytetu, Vol. 5 (161), pp. 100-108. DOI: 10.13140/RG.2.2.33613.23528 
Concept of reforming the labor protection management system in Ukraina. Available at: https://zakon.rada.gov.ua/laws/show/9892018-\%D1\%80?lang=ru\#Text (accessed June 18, 2020)

Early emergency detection system: patent 53753 of Ukraine for useful model: G08B 19/00. № u201009986; declared 12.08.10; published 11.10.10. Available at: https://base.uipv.org/searchINV/search.php ?action=viewdetails\&IdClaim=150897 (accessed June 18, 2020)

Framework Directive No. 89/391/EEC “On the implementation of measures to improve occupational safety and health". Available at: https://zakon.rada.gov.ua/laws/show/994_b 23\#Text (accessed June 18, 2020)

Halil V.V. (2018). "Improvement of the system of risk management in the machine-building industry". Thesis abstract of Cand. Sc. (Engineering). 05.26.01. Kharkov, Ukraine. Available at: http://ndiop.kiev.ua/sites/ default/files/file/\%D0\%90\%D0\%B2\%D1\%82 \%D0\%BE\%D1\%80\%D0\%B5\%D1\%84\%D0\%B5 \%D1\%80\%D0\%B0\%D1\%82\%20\%D0\%A5\%D0 \%B0\%D0\%BB\%D1\%96\%D0\%BB\%D1\%8C\%20 \%D0\%92.pdf

Information-management system of complex safety control of a dangerous production facility: patent 2536351 of RF for useful model G06F17/00, G08B23/00, G01W1/00. №2013130085/08; declared 02.07.2013; published 20.12.2014. Available at: http://www.freepatent.ru/patents/2536351 (accessed June 18, 2020)

Integrated monitoring system for monitored objects: patent 2417451of RF for useful model. G08B 19/00 (2006.01). № 2006123352/08; declared 03.07.2006; published 20.01.2008. Available at: http://www.freepatent.ru/images/patents/4 3/2417451/patent-2417451.pdf
Ismael S. Sánchez - Herrera, Mario J. Donate. (2019). Occupational safety and health (OSH) and business strategy: The role of the $\mathrm{OSH}$ professional in Spain. Safety Science, Vol. 120, pp. 206-225. DOI: 10.1016/j.ssci.2019.06.037

Kruzhilko O. E., Watchman Ya. B., Lutak Z. I. and Prachnikov N. A. (2017). "Methodical principles of industrial risk estimation in preventive measures planning". Problems of labor safety in Ukraine: collection of scientific works, Vol. 33, pp. 15-21.

Lesenko G. G. (2011). “On the issue of evaluating the effectiveness of the labor protection management system at the enterprise". Problemi ohoroni praci v Ukrayini, no. 20, pp. 129-139

System of automated complex protection against occupational hazards: patent 118077 of Ukraine for useful model. G08B 25/14 (2006.01), G08B 23/00, G08B 21/02 (2006.01). № a201804982; declared 07.05.2018; published 27.08.2018. Available at: http://base.uipv.org/searchINV/search. php?action=viewdetails\&IdClaim $=252456$ (accessed June 18, 2020)

Tretyakov O.V., Nestereko S.V., Doronin E.V., Golovenko M.M. (2018). "The risk-oriented approach to determining working conditions in the workplace". Stroitelstvo, materialovedenie, mashinostroenie, Vol. 105, pp. 131-138. DOI: 10.30838/ P. CMM.2415.250918.126.142

Zdanovskiy V. G., Gogitashvill G. G., Stepanishin V. M. (2016). "New in the occupational health and safety management system based on a systematic approach and implementation of European standards". Problems of labor safety in Ukraine: collection of scientific works, Vol. 31, pp. 3-11. 